\title{
Integrating QFD for Product-Service Systems with the Kano model and fuzzy AHP
}

Nicolas Haber, Mario Fargnoli and Tomohiko Sakao

The self-archived postprint version of this journal article is available at Linköping University Institutional Repository (DiVA):

http:/ / urn.kb.se/ resolve?urn=urn:nbn:se:liu:diva- 152475

N.B.: When citing this work, cite the original publication.

This is an electronic version of an article published in:

Haber, N., Fargnoli, M., Sakao, T., (2018), Integrating QFD for Product-Service Systems with the Kano model and fuzzy AHP, Total quality management and business excellence (Online).

https:/ / doi.org/ 10.1080/ 14783363.2018.1470897

Original publication available at:

https:/ / doi.org/ 10.1080/ 14783363.2018.1470897

Copyright: Taylor \& Francis (Routledge) (SSH Titles)

http:// www.routledge.com/ 


\section{Integrating QFD for Product-Service Systems with the Kano model and fuzzy}

\section{AHP}

Haber Nicolas ${ }^{\mathrm{a}^{*}}$, Fargnoli Mario ${ }^{\mathrm{a}^{* *}}$, Sakao Tomohiko ${ }^{\mathrm{b} * * *}$

${ }^{a}$ Department of Mechanical and Aerospace Engineering, "Sapienza - University of Rome", via Eudossiana 18, 00184 Rome, Italy

${ }^{b}$ Division of Environmental Technology and Management, Department of Management and Engineering, Linköping University, 58183 Linköping, Sweden

* Corresponding author: nicolas.haber@uniroma1.it

** Co-author: mario.fargnoli@uniroma1.it

*** Co-author: tomohiko.sakao@liu.se

\section{Abstract}

The paper proposes a systematic procedure for the development of Product-Service Systems (PSSs) by focusing on the analysis of customer requirements, and the selection of those that can practically enhance the offerings' value. With this goal in mind, the Quality Function Deployment for Product Service Systems (QFDforPSS) method was augmented by means of the Kano model to filter the customers' needs and transform the attractive ones into Receiver State Parameters (RSPs), as the cornerstone of QFDforPSS. Then, to properly assess these parameters and their inherent uncertainty, the Fuzzy Analytical Hierarchy Process (FAHP) method was also integrated into the procedure. To validate the proposed procedure, it was implemented in a case study in the medical devices sector, in collaboration with a haemodialysis equipment manufacturer, which operates in a regulated market of product-oriented services.

\section{Keywords}

Product-Service System (PSS), service design, Quality Function Deployment (QFD), customer requirements, medical devices, regulated market

\section{Introduction}

In recent years, the attention paid to the development of Product Service Systems (PSSs) has 
increased greatly, as demonstrated by the ever-larger number of articles illustrating the need for further research on this topic (Green, Davies, \& Ng, 2017; Matschewsky, Kambanou, \& Sakao, 2017; Reim, Parida, \& Ortqvist, 2014). The main reasons for such a trend can be summarized as follows: the development of PSSs provides engineers with an opportunity to achieve better environmental performance and to increase the product's value during its whole lifecycle (Fargnoli, De Minicis, \& Tronci, 2012; Sousa-Zomer, \& Cauchick-Miguel, 2017a; Vezzoli \& Ceschin, 2015). Furthermore, the integration of services with a product can be utilised to increase the satisfaction of their receivers (Sakao \& Shimomura, 2007) while providing the implementing company with a competitive edge and a market advantage (Tukker, 2015). The PSS approach is based on the integration of both the physical (tangible) characteristics of a product and the immaterial ones, i.e. services provided during the product's use (Sakao, Napolitano, Tronci, Sundin, \& Lindahl, 2008). The literature exhibits different PSS models, which can be classified into three main categories: product-oriented, use-oriented and result-oriented services (Tukker, 2004). Depending on the type of offering, different options for the creation of value and its delivery can be found (Tan, Matzen, McAloone, \& Evans, 2010).

Even when a set of basic product-oriented services are expected by customers, manufacturers have the opportunity to expand their business and generate more value and/or reduce costs from them, as pointed out by Ulaga and Reinartz (2011). Thus, they are expected to satisfy the customers' needs and expectations efficiently, by means of their "design-to-service” capabilities (Oliva \& Kallenberg, 2003; Ulaga \& Reinartz, 2011). To achieve such a goal, it is fundamental to identify the PSS customers properly, to understand what their requirements are, and, more importantly, to distinguish between the basic and attractive requirements. Such an 
understanding would allow a better comprehension of the customers' requirements and hence an improvement in the quality of the offered services (Materla, Cudney, \& Antony, 2017).

At the same time, once the customers' requirements are defined, it is also important to effectively transform them into design requirements (Cho, Kim, \& Kwak, 2016), while avoiding possible conflicts between the service and the product attributes of the PSS. As noted by Song and Sakao (2016), it is more challenging to identify and solve the conflicts of the service attributes of a PSS since they are more intangible and harder to explicate than the conventional product attributes of a product-reliant solution. Similarly, Hakanen, Helander, and Valkokari (2016) brought to light the need to further investigate the customer's perceptions of the value associated with a PSS to address the manufacturer's strategies. The latter is pivotal to minimise ambiguities when designing quality into offerings (Lo, Shen, \& Chen, 2016). Additionally, different techniques for the assessment of customer requirements (CRs) lead to different results, thus their comparative evaluation should be investigated to reduce inconsistencies and misleading customer information (Franceschini \& Maisano, 2015). Thus, given that the performance of services and the resulting customer satisfaction are highly subjective and not easily quantifiable due to their intangibility (Aurich, Mannweiler, \& Schweitzer, 2010; Regan, 1963), the need for a proper understanding of service design through an effective approach based on a systematic procedure for developing services that incorporates customer requirements properly arises from numerous studies (e.g. in (Haber \& Fargnoli, 2017a; Kim \& Yoon, 2012; Rapaccini, Saccani, \& Pezzotta, 2013; Sabbagh, Rahman, Ismail, \& Hussain, 2016)). Moreover, as argued by Mittermeyer, Njuguna, and Alcock (2011), the achievement of such a goal appears more difficult for companies operating in regulated markets, such as the healthcare sector, where the customers (i.e. the hospitals) need to operate following public procurement rules and it is more difficult for the end-users (i.e. doctors and 
technicians) to influence the decision-making process when purchasing products and services (Bergman and Lundberg, 2013; Lingg, Merida-Herrera, Wyss, \& Durán-Arenas, 2017). Hence, despite the great potential of PSS in this sector (Marceau \& Basri, 2001; Oliva \& Kallenberg, 2003; Xing, Rapaccini, \& Visintin, 2017), additional research is needed to address the customer demand properly (Moultrie, Sutcliffe, \& Maier, 2015; Baines, et al., 2017).

The purpose of the present study is to address these research challenges. In more concrete terms, our research questions can be summarized as follows:

RQ1. How can a manufacturer translate CRs effectively to develop a solution in a regulated market and simultaneously augment customer satisfaction?

RQ2. How can a PSS provider address data uncertainty of CRs?

To answer these research questions, the paper aims at proposing a structured approach, based on the Quality Function Deployment (QFD) method (Akao, 1990) and its adaptation to PSS development, named Quality Function Deployment for PSS (QFDforPSS) (Arai and Shimomura, 2005; Sakao, Birkhofer, Panshef, \& Dörsam, 2009). The effectiveness of the QFDforPSS is augmented by its integration with the Fuzzy Analytical Hierarchy Process (FAHP) method (Kamvysi, Gotzamani, Andronikidis, \& Georgiou, 2014) as a means of dealing with the vagueness of services in the QFD (Cho et al., 2016). In addition, the integration of QFDforPSS with the Kano model (Kano, Seraku, Takahashi, \& Tsjui, 1984) can allow engineers to better analyse the market demand as to reduce the risk of customer dissatisfaction (Tontini, 2007). The research method adopted is a "case study" approach (Pawar, Beltagui, \& Riedel, 2009; Voss, Tsikriktsis, and Frohlich, 2002; Yin, 2003) and to investigate its applicability in practice, it was implemented in the medical devices sector, where effective service strategies are essential for the profitability of the manufacturer (Materla et al., 2017). In detail, the article is organized as follows: section 2 
analyses the state of the art of QFD and its extensions in service engineering. Section 3 presents our research approach, and its application in a "design-to-service" context is described in section 4. Section 5 discusses the obtained results, while section 6 concludes the article.

\section{Background and research motivations}

The QFD method is considered one of the most well-known and widespread tools to capture the customers' needs and expectations and to translate them into practical and usable information for designers. A large amount of literature can be found on its use in different contexts (e.g. in (Chan \& Wu, 2002; Fargnoli, 2005; Fargnoli, Costantino, Di Gravio, \& Tronci, 2018; Raharjo, Xie, \& Brombacher, 2011; Sivasamy, Arumugam, Devadasan, Murugesh, \& Thilak, 2016; Xie, Goh, \& Tan, 2003)), on its benefits and limitations, as well as on its extensions and supporting tools (Carnevalli \& Miguel, 2008; Franceschini, Galetto, Maisano, \& Mastrogiacomo, 2015; Kahraman, Ertay, \& Büyüközkan, 2006; Sakao, 2007; Temponi, Yen, \& Tiao, 1999; Vinayak \& Kodali, 2013; Zare Mehrjerdi, 2010; Zhang, Tong, Eres, Wang, \& Kossmann, 2015).

\subsection{Quality Function Deployment for PSS}

QFDforPSS represents a specific adaptation of QFD in the PSS development context (Fargnoli and Sakao, 2017), with the aim of supporting engineers in the proper identification, assessment and characterization of customer requirements while efficaciously drawing up a PSS (Hara, Arai,

\& Shimomura, 2009). Although the QFDforPSS method uses a similar mechanism to the traditional one, some key features characterize it differently. Essentially, it consists of two phases, schematized in Figure 1. 

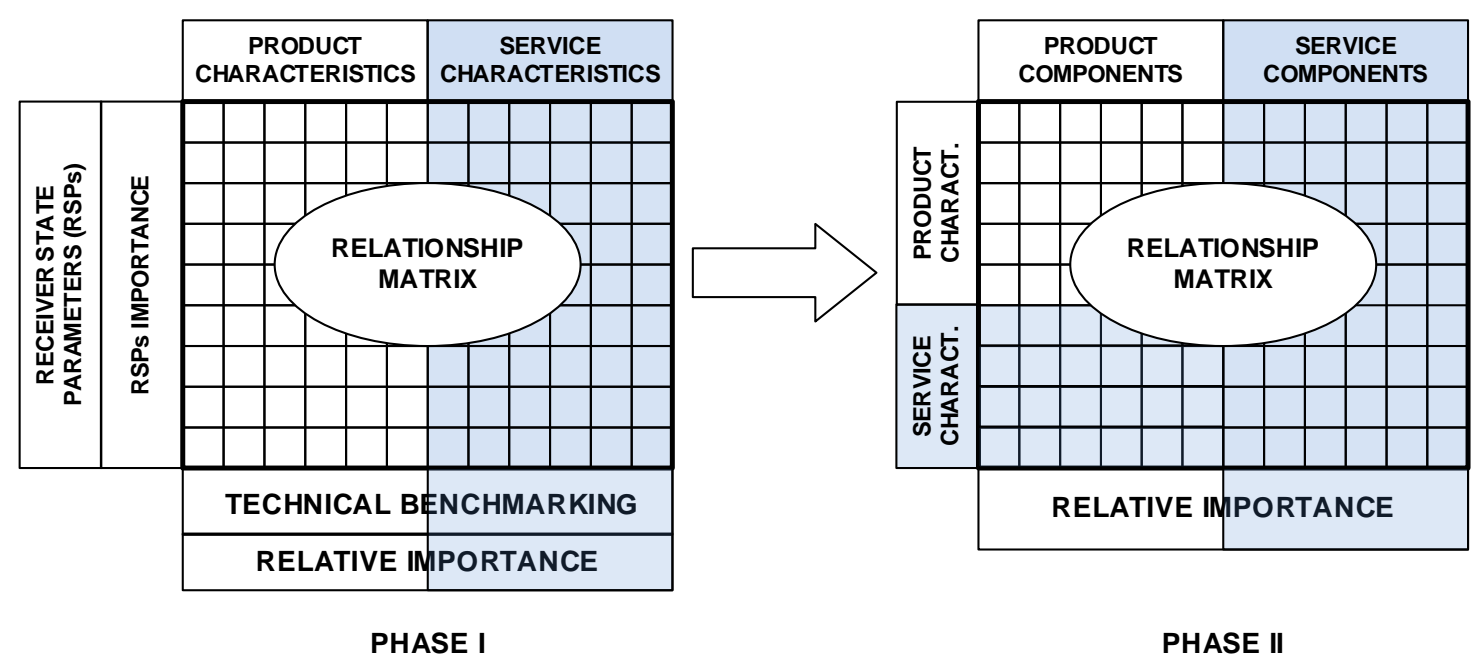

Figure 1. Scheme of the "QFD for PSS" method (adapted from (Fargnoli and Sakao 2017).

The input of the first phase of the method is represented by the "Receiver State Parameters" (RSPs), i.e. any aspect that can have a positive or a negative effect on the PSS receiver. RSPs are classified into values (positive effect) and costs (negative effects) depending on whether the customers like them or not (Sakao, Birkhofer, Panshef, \& Dörsam, 2009). The use of RSPs instead of traditional Customers Requirements (CRs) allows engineers to evaluate the mutual comparability among multiple RSPs more coherently, and at the same time, it facilitates the integration of multiple stakeholder needs. As the output of the first phase, the characteristics of both the product and the service (the so-called "Engineering Characteristics" (ECs) in traditional QFD) are listed and assessed. Then, the second phase of the method provides the list of main components that a PSS should include to successfully augment customer value.

\subsection{Quality Function Deployment supporting tools}

As mentioned before, numerous studies propose QFD's improvement options by means of supporting methods and techniques (Abdolshah \& Moradi, 2013; Asadabadi, 2014; Bereketli \& Genevois, 2013; Büyüközkan, Ertay, Kahraman, \& Ruan, 2004; Lee, Sheu, \& Tsou, 2008; Wang 
\& Chen, 2012; Zheng, Zhu, Tian, Chen, \& Sun, 2012). Without going into details, it has to be noted that the prevailing literature (e.g. Carnevalli, Miguel \& Calarge, 2010; Franceschini \& Maisano, 2015) agrees on recognizing that one of the most effective ways to improve the effectiveness of QFD consists in understanding the customers' needs (the so-called "Voice of Customers”, VoCs) in the most efficacious way, as well as in rating the customers' preferences as accurately as possible. Accordingly, in this section we limited our analysis to the basic information concerning the tools we used in our study:

- The Kano model (Kano et al., 1984),

- The AHP method, developed by Saaty (1990),

- Fuzzy logic sets (Abdolshah \& Moradi, 2013; Kamvysi et al., 2014; Patriarca, Di Gravio, Mancini, \& Costantino, 2016).

\subsection{Research motivations}

Integrated approaches which combine the above-mentioned tools to better quantify customer information can be found in the literature: for example, the Kano integrated QFD (Tontini, 2007), fuzzy QFD (Liu, 2009), fuzzy AHP-QFD (Pakizehkar, Sadrabadi, Mehrjardi, \& Eshaghieh, 2016), etc. These variants serve as a QFD framework where the relationships between CRs and ECs as well as among the CRs are analysed to address the interdependencies among the CRs and the impact an EC has on a CR (Asadabadi, 2014). Additionally, Ulaga and Loveland (2014), pointed out that differently from a product-centric environment, in PSSs, companies have to deal with a "fuzzy front end" to understand what customers really need and how to combine goods and services to achieve such a goal.

In a fuzzy logic context, crisp numbers are transformed into fuzzy numbers considered as a 
probability distribution, more frequently defined as Triangular Fuzzy Numbers (TFNs) since they can be easily handled and manipulated (Liu \& Tsai, 2012). The use of fuzzy logic and TFNs allows overcoming the ambiguity and biasness of subjective evaluations and developing effective design strategies (Liu \& Wang, 2010). Using the crisp-fuzzy AHP scale (Chowdhury \& Quaddus, 2016), the weights of the CRs are obtained and the correlations with the ECs are defined, enabling decision making with estimated or uncertain values. A further advantage is its ability to handle multiple inputs and outputs in a system.

The integrated use of the FAHP and QFD is a well-known approach to reduce the house of quality’s (HoQ) drawbacks (Onar, Büyüközkan, Öztayşi, \& Kahraman, 2016). The fuzzy set theory and group decision-making techniques such as the AHP can be considered effective means to deal with vagueness, uncertainty, and diversity in decision-making and to compare customer requirements (Sousa-Zomer \& Cauchick Miguel, 2017b). In a PSS context, some examples of integrated QFD models can be found as well. For instance, Jiao and Chen (2006) argued that such an approach can support engineers in dealing with the vagueness and imprecision that characterize information concerning customer requirements. Geng, Chu, Xue, and Zhang (2010) developed an integrated approach based on the FAHP to augment the assessment of the QFD's engineering characteristics (ECs). Accordingly, Song et al. (2013) integrated the QFD and FAHP methods in a procedure aimed at selecting and assessing the PSS requirements from a life-cycle point of view. Sousa-Zomer and Miguel (2017b) proposed a FAHP-QFD procedure to prioritize the stakeholders' requirements in the three sustainability dimensions (environmental, social and economic), with the goal of addressing the development of PSS concepts more effectively. Nevertheless, these remarkable studies do not consider the risk of customer dissatisfaction when dealing with PSS development nor provide practical hints to shift from the customer requirements to the elicitation 
of PSS elements that can influence the state of the PSS receivers effectively. The latter decisionmaking problem is relevant especially in the case of PSSs in regulated markets, where some services are normally provided (Oliva \& Kallenberg, 2003; Hatzopoulos \& Stergiou, 2011). Hence, to augment customer satisfaction, the selection of the customers' needs and expectations has to go beyond mandatory requirements (Gelderman, Ghijsen, \& Brugman, 2006; Fargnoli, Costantino, Tronci, \& Bisillo, 2013), eliciting the high-level “front-end” requirements. In other words, in a PSS context, customer requirements involve ambiguities and vagueness (Aurich, Mannweiler, \& Schweitzer, 2010; Huang \& Hsu, 2016), which the manufacturer (PSS provider) has to deal with. Consequently, for a better decision-making, the general customer requirements have to be "filtered" to bring to light the PSS elements that can increase customer satisfaction effectively. Therefore, the present work can be considered as a first attempt to address these issues, augmenting the research knowledge on customer requirements management in a PSS context, since the extant literature provides no report on QFD dealing with PSS incorporating customer satisfaction and vagueness.

\section{Research approach}

Based on the motivations explained in the previous section, the research approach was aimed at the definition of a systematic procedure for developing PSSs that properly incorporate CRs by focusing on the value-creating attributes that can enhance a PSS especially in the case of productoriented services. This approach is based on the QFDforPSS method, augmented by the integration of the Kano model, and the FAHP approach (Figure 2). 


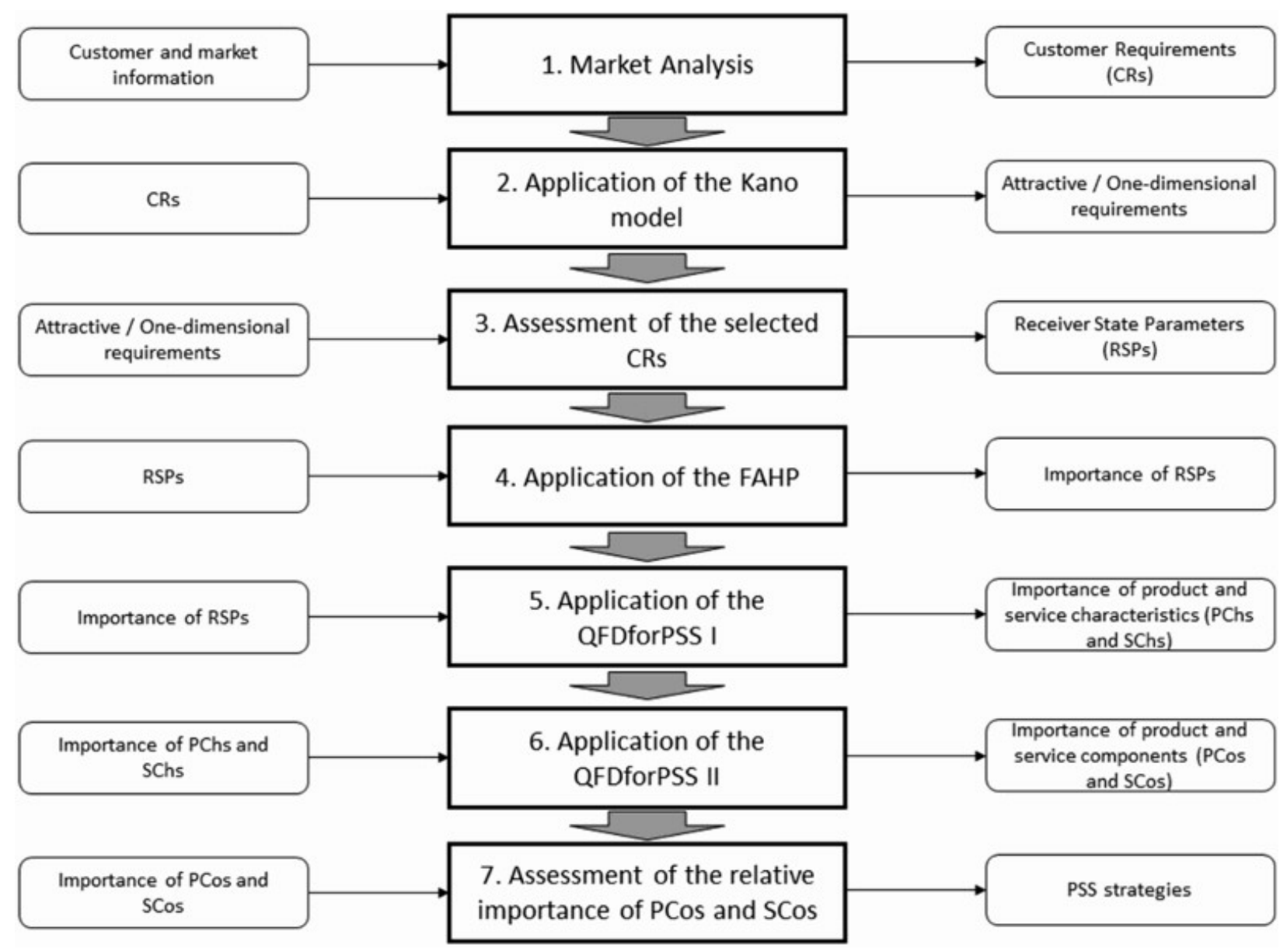

Figure 2. Scheme of the research approach.

More in detail, the following features characterize the proposed procedure.

(1) Market analysis: market surveys and questionnaires for the customers' involvement constitute the basis for the definition of CRs.

(2) Application of the Kano model: the individuation of the attractive and one-dimensional CRs by means of the Kano model, since the attractive CRs create more room for innovative means for profit generation and cost reduction opportunities (Finster, Eagan, \& Hussey, 2001; Matzler \& Hinterhuber, 1998). Following Kano’s criteria for the classification of the CRs, one-dimensional CRs represent the measurable technical performances of the PSS that the customer expresses explicitly. These CRs are usually 'standard' and specified by 
the customer prior to using the PSS (Madzik, 2016). In other words, the Kano model helps in filtering CRs by removing the basic ones, which are a must-be in a regulated market. This allows engineers to define the requirements whose fulfilment could contribute to an increased customer value, leading to the quality strategy to follow (Cheng and Chiu, 2007).

(3) Assessment of the selected CRs: a translation process is carried out by means of a group of experts to transform the CRs into RSPs, which allows a more coherent integration of the stakeholders' requirements and hence a more reliable evaluation of their comparability. This is necessary because CRs are sometimes expressed vaguely and in such a way that they are difficult to be compared. Based on this, the group of experts is also able to better define the characteristics of the product (PChs) and the characteristics of the service (SChs).

(4) Application of the FAHP: the prioritization of the RSPs is performed by means of the FAHP, determining the importance level of each RSP by pairwise comparisons (Saaty, 1990) and refining it through the fuzzy logic approach (Singh \& Prasher, 2017). More precisely, the "crisp" results of the pairwise comparisons are transformed into TFNs and then de-fuzzified as per the transformations described by Kamvysi et al. (2014).

(5) Application of the QFDforPSS (Phase I): the first phase of the method allows engineers to assess the relative importance of each PCh and SCh, as well as to define the level of the product-service integration.

(6) Application of the QFDforPSS (Phase II): in the second phase, the components of the product (PCos) and of the service (SCos) are defined and their relative importance is calculated. 
(7) Assessment of the relative importance of PCos and SCos by means of a group of experts, which facilitates finding possible PSS improvement strategies.

It has to be pointed out that the proposed procedure reveals a novel approach aimed at augmenting the creation of value in PSS development by means of the QFDforPSS. Actually, the use of the Kano model screens the CRs, supporting engineers to select those that are able to augment customer satisfaction. Then, a translation process is needed to combine the results of the Kano model with the QFDforPSS method to develop feasible solutions that satisfy those requisites effectively. Furthermore, to narrow the gaps between the PSS characteristics and the customers' expectations, the FAHP approach is applied with the goal of merging multi-respondent preferences and prioritizing them in an accurate manner. This is in line with the research outcome by $\mathrm{Li}, \mathrm{He}$, Wang, and Zhang (2016), who highlighted the need to evaluate the accuracy and correlations of the PSS elements.

\section{Research implementation}

The study was carried out in the medical device sector where the need for an appropriate service strategy is emphasized (Ulaga \& Reinartz, 2011; Lee, Ru, Yeung, Choy, \& Ip, 2015). As observed by Oliva and Kallenberg (2003), this is a typical case of industries where, although service offerings are well known, they are normally provided in the context of strict regulations. Consequently, the implementation of integrated product and services based on the customers' needs and expectations is more challenging (Mittermeyer et al., 2011).

In particular, the work concerned the implementation of our approach in a company operating in the renal support devices market. This company produces haemodialysis devices, which are ordinary products in the sector, and provides both the equipment and all the services needed for its 
use. The company has service centres in all regions nationwide and it is seeking to improve the services related to its equipment to enhance the value of its offerings. Hence, it can be considered a representative case of companies providing both products and services in the medical device sector (Cho, Kim, \& Kwak, 2016).

\subsection{Customer requirements identification}

As a first step, a market survey was conducted in collaboration with a group of the company's experts (i.e. a marketing manager, the product development manager and the director of the scientific affairs unit). It is worth noting that, to respect the privacy and ethical concerns related with the use of the data collected, as well as to avoid any potential bias from the collaboration with the company's experts, the involvement of the latter was managed as follows. The expert's group was used for technical support in different moments of the case study development when a multidisciplinary judgment was needed. With this aim in mind, an adaptation of the Delphi technique was used (Buckley, 1994; Azevedo, Govindan, Carvalho, \& Cruz-Machado, 2013): i.e. while the participants knew each other, individual responses to questions were asked separately and kept anonymous. Moreover, the data used as input in the meetings was provided by means of structured (e.g. in the case of the fulfilment of the QFDforPSS relationship matrices) or semi-structured (e.g. in the case of the definition of the PCos) questionnaires where any reference to the source was omitted.

Since most of the company's customers are represented by public hospitals and clinics, and the public procurement system is based on calls for tender (Bergman and Lundberg, 2013), we screened the invitations to tender issued in a 24-month period (2015-2016) at the national level and selected 25 of them that fit the company's target (for instance, invitations that included the fitting out of haemodialysis room ex novo were not taken into account). This activity included the 
analysis of both the tangible (technical) and the intangible (service) characteristics required by the invitations, as well as the criteria used to assess the tenders' offerings. Hence, we further analysed these data to eliminate the requirements concerning the characteristics related to the basic functioning of the device. This activity was carried out with the support of the company's group of experts to better separate the basic elements of the PSS from the other requirements. For example, characteristics such as "presence of a display or a monitor", "alarm system to monitor the presence of air", "wheels to move the machine from one room to another", or "maintenance service during the contract period" were considered as standardized elements of this type of PSS representing the so-called "cutting edge" of the sector.

Then, we developed a questionnaire aimed at gathering the importance of the CRs. It was submitted to 47 customers (i.e. the doctors who use the haemodialysis devices on a daily basis, belonging to different public hospitals operating as organisational units for public procurement). The hospitals were selected considering their geographical locations and the population of the areas they cover in order to obtain a homogenous distribution in the northern, southern and middle parts of the country. Moreover, to prevent any potential bias, the questionnaires were sent under the university edge, omitting any manufacturer related information. Of the 47 customers, 20 of them provided a complete answer. They were asked to evaluate the importance of each CR using a (1 to 5) scale and their current level of satisfaction per each requirement using a $(-3,+3)$ scale (Tontini, 2007). The classification of the requirements according to the Kano categories was performed using the Customer Satisfaction Coefficient (CSC) indices, which calculate the percentage of customers satisfied $\left(\mathrm{CSC}_{s}\right)$ with the functional form of the question and the percentage of dissatisfied customers with the dysfunctional form $\left(\mathrm{CSC}_{d}\right)$ (Matzler \& Hinterhuber, 1998). The categories are defined as Attractive (A), Must-be (M), One-dimensional (O), 
Indifferent (I), Reversal (R) and Questionable (Q) while the coefficients are calculated as per equations (1) and (2) (Berger et al., 1993).

$$
\begin{aligned}
\mathrm{CSC}_{\mathrm{s}} & =\frac{A+O}{A+O+M+I} \\
\mathrm{CSC}_{\mathrm{d}} & =\frac{M+O}{A+O+M+I}
\end{aligned}
$$

Then, the requirements belonging to Attractive (A) and One-dimensional (O) Kano categories were selected (Table 1).

Table 1. Attractive and One-dimensional requirements.

\begin{tabular}{|l|l|}
\hline \multicolumn{1}{|c|}{ Attractive Requirements } & \multicolumn{1}{c|}{ One-dimensional Requirements } \\
\hline CR1 - User-friendly equipment & CR2 - Haemodialysis process monitoring \\
\hline CR6 - Easy maintenance & CR3 - Availability of a self-testing system \\
\hline CR7 - Quick setting before each treatment & $\begin{array}{l}\text { CR4 - Quick replacement of malfunctioning } \\
\text { devices }\end{array}$ \\
\hline CR8 - System upgradability & CR5 - Quick intervention when requested \\
\hline $\begin{array}{l}\text { CR10 - Provision of consumables with a low } \\
\text { environmental impact }\end{array}$ & CR9 - Remote technical support \\
\hline
\end{tabular}

It should be noted that in this sector a full risk service, as well as the availability of additional equipment in the stock (the so-called "back-up” equipment), should be considered as standard requirements, thus they were also omitted in the definition of the CRs. The selected requirements are of a general nature, i.e. they can be satisfied by a service (intangible), by a product (tangible), or by a combination of both. Hence, to support engineers in better understanding what can enhance the customers' value and how to pursue it, they need to be translated into functions, i.e. into RSPs, which consist of quantitative, observable and controllable value (Arai \& Shimomura, 2005).

\subsection{Definition of RSPs and Product and Service Characteristics}

In collaboration with the group of experts, the selected requirements were analysed and translated into the following RSPs: 
RSP 1. Easiness to use.

RSP 2. Ergonomics (interface operator-machine).

RSP 3. Full monitoring (real-time information during the process).

RSP 4. Short time for a replacement.

RSP 5. Short time for an intervention.

RSP 6. Availability.

RSP 7. Eco-friendliness and biocompatibility.

RSP 8. Upgradability.

RSP 9. Technical support availability.

RSP 10. Inclusion of consumables.

Similarly, with the support of the group of experts, the characteristics of the solution that would meet the RSPs were defined, distinguishing between product and service characteristics (PChs and SChs respectively (Sakao, Shimomura, Sundin, \& Comstock, 2009)) as follows:

PCh1 - Product size: the machine’s dimensions should be adequate to allow its easy use and transportation.

PCh2 - Monitor type: the monitor size and resolution should be adequate.

PCh3 - Mean Time Before Failure (MTBF): the equipment must function for prolonged working hours before the occurrence of failures.

PCh4 - Software modularity: a modular design enables easier upgrades and interventions. PCh5 - Number of setup operations specific to the product: the number of steps to carry out for the installation and removal of the consumables should be minimum.

PCh6 - Alarm warning feature: a malfunctioning alarm should arise by means of a visual or sound signal to inform the user. 
PCh7 - Availability of a self-testing system to be used before each treatment.

PCh8 - Treatments' data storage in the system hard disk.

PCh9 - Eco-friendliness of consumables (e.g. filters and solutes).

PCh10 - Quality of product manual: the product should be accompanied by a manual describing its components and guiding the user through its calibration and use, including interactive software.

SCh1 - Information for intervention requests.

SCh2 - Calendar time of training: periodic training for the correct use of the machine, notably when updates are available.

SCh3 - Time for response: short time to reply an inquiry and intervene.

SCh4 - Calendar time of consumables delivery: consumables are delivered according to an agreed-on schedule.

SCh5 - Operational time of customer care: the customer care unit should be available to reply to customer calls.

SCh6 - Quality of customer care: customer care should have the capacity to assist the customer effectively.

\section{3. $R S P$ s prioritization}

The obtained RSPs are supposed to be quantified and prioritized according to the CRs to define which RSPs are more important. In other words, such an approach allows designers to better understand which RSP holds the highest impact on the holistic performance and quality of the solution. To do so, the customers who provided full responses to the market survey (Section 4.1) were interviewed and asked to evaluate the importance of each CR compared to another by adopting a pairwise comparison approach as per Saaty’s scale (Saaty, 1990). 
The importance levels of each RSP are then utilized as the inputs of the comparison matrix where a row $\mathrm{RSP}_{\mathrm{i}}$ is prioritized over a column $\mathrm{RSP}_{\mathrm{j}}$ using equation (3).

$$
R S P_{i}=\frac{1}{R S P_{j}}
$$

Consequently, the shift from crisp numbers to TFNs was carried out using the transformation exhibited by Kamvysi et al. (2014) to apply the FAHP method. In practice, each crisp RSP importance level is converted to a TFN $(l, m, u)$, where $l, m$, and $u$ represent the smallest possible value, the most promising value, and the largest possible value respectively (Zaim et al., 2014). The pairwise comparison scale and the crisp-to-fuzzy transformation criteria are shown in Table 2.

Table 2. The scale for defining the importance of RSPs.

\begin{tabular}{|c|c|c|l|l|}
\hline $\begin{array}{c}\text { Importance } \\
\text { level (crisp) }\end{array}$ & TFN & Reciprocal TFN & Definition & \multicolumn{1}{|c|}{ Explanation } \\
\hline 1 & $(1,1,1)$ & $(1,1,1)$ & $\begin{array}{l}\text { Equal } \\
\text { importance }\end{array}$ & $\begin{array}{l}\text { The two RSPs are of equal } \\
\text { importance }\end{array}$ \\
\hline 2 & $(1,2,3)$ & $(1 / 3,1 / 2,1)$ & & \\
\hline 3 & $(2,3,4)$ & $(1 / 4,1 / 3,1 / 2)$ & $\begin{array}{l}\text { Moderate } \\
\text { importance }\end{array}$ & $\begin{array}{l}\text { One RSP is a little more favourable } \\
\text { over another }\end{array}$ \\
\hline 4 & $(3,4,5)$ & $(1 / 5,1 / 4,1 / 3)$ & & \\
\hline 5 & $(4,5,6)$ & $(1 / 6,1 / 5,1 / 4)$ & $\begin{array}{l}\text { Strong } \\
\text { importance }\end{array}$ & $\begin{array}{l}\text { One RSP is strongly preferred over } \\
\text { another }\end{array}$ \\
\hline 6 & $(5,6,7)$ & $(1 / 7,1 / 6,1 / 5)$ & & \\
\hline 7 & $(6,7,8)$ & $(1 / 8,1 / 7,1 / 6)$ & $\begin{array}{l}\text { Very strong } \\
\text { importance }\end{array}$ & $\begin{array}{l}\text { One RSP is heavily favoured over } \\
\text { another }\end{array}$ \\
\hline 8 & $(7,8,9)$ & $(1 / 9,1 / 8,1 / 7)$ & & \\
\hline 9 & $(8,9,10)$ & $(1 / 10,1 / 9,1 / 8)$ & $\begin{array}{l}\text { Extreme } \\
\text { importance }\end{array}$ & $\begin{array}{l}\text { One RSP is significantly dominant } \\
\text { compared to another }\end{array}$ \\
\hline \multicolumn{5}{|c|}{$2,4,6$ and 8 are used to describe intermediate values of importance } \\
\hline \multicolumn{5}{|c|}{} \\
\hline
\end{tabular}

The de-fuzzification process follows as per equation (4), and the results were then verified for 
consistency in accordance with Kwong and Bai (2003).

$$
R S P \text { importance }_{\text {crisp }}=\frac{(4 m+l+u)}{6}
$$

The final results of the RSPs’ prioritization (C crisp values) are shown in Table 3.

Table 3. C-Crisp values.

\begin{tabular}{|l|c|c|c|}
\hline Receiver state parameters & C crisp & C relative & Rank \\
\hline RSP 1. Easiness to use & 0.64 & $6.14 \%$ & 5 \\
\hline RSP 2. Ergonomics (interface operator-machine) & 0.44 & $4.21 \%$ & 9 \\
\hline RSP 3. Full monitoring & 0.43 & $4.14 \%$ & 10 \\
\hline RSP 4. Short time for replacement & 1.29 & $12.37 \%$ & 4 \\
\hline RSP 5. Short time for intervention & 1.98 & $18.94 \%$ & 2 \\
\hline RSP 6. Eco-friendliness and biocompatibility & 1.41 & $13.52 \%$ & 3 \\
\hline RSP 7. Availability & 2.66 & $25.47 \%$ & 1 \\
\hline RSP 8. Upgradability & 0.60 & $5.72 \%$ & 6 \\
\hline RSP 9. Technical support availability & 0.53 & $5.09 \%$ & 7 \\
\hline RSP 10. Inclusion of consumables & 0.46 & $4.40 \%$ & 8 \\
\hline
\end{tabular}

4.4. Phase I of the QFDforPSS method

Based on these results and their validation, the first phase of the QFDforPSS method was implemented. The PChs and SChs were combined with the RSPs in the relationship matrix using a 1-3-9 rating scale, where 1 indicates a weak relationship, 3 a medium one and 9 a strong one. When a relationship does not exist, the cell is left blank. For example, as far as the satisfaction of RSP 3 (Full monitoring) is concerned, product characteristics (PCh 2, PCh 6, PCh 7 and PCh 10), and service characteristics (SCh 2, SCh 5 and SCh 6) mainly related to the support to users were found important. The output of this phase consists in obtaining the Absolute Importance (AI) of each PCh and SCh and consequently their Relative Importance (RI) values (Table 4). 
Table 4. QFD for PSS phase I.

\begin{tabular}{|c|c|c|c|c|c|c|c|c|c|c|c|c|c|c|c|c|c|c|c|}
\hline & 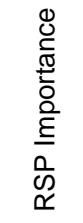 & 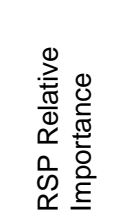 & 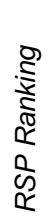 & $\frac{-1}{\bar{U}}$ & $\frac{N}{U}$ & $\frac{M}{U}$ & $\begin{array}{l}\frac{J}{U} \\
\frac{D}{Q}\end{array}$ & $\begin{array}{l}\frac{L}{D} \\
\frac{\Omega}{\Lambda}\end{array}$ & $\begin{array}{l}0 \\
\frac{0}{U} \\
\square\end{array}$ & $\frac{\hat{\sigma}}{\mathrm{D}}$ & $\begin{array}{l}\frac{\infty}{U} \\
\square\end{array}$ & $\begin{array}{l}\frac{O}{U} \\
\frac{1}{\Lambda}\end{array}$ & $\begin{array}{l}\text { 엄 } \\
\frac{1}{0} \\
\frac{0}{0}\end{array}$ & 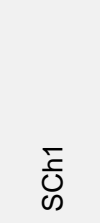 & $\begin{array}{l}\text { Ũ } \\
\text { Un }\end{array}$ & $\frac{m}{U}$ & 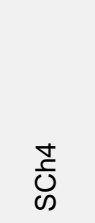 & $\begin{array}{l}\frac{L}{U} \\
\text { Un }\end{array}$ & 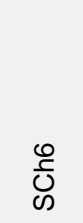 \\
\hline RSP 1 & 0.64 & $6.13 \%$ & 5 & 1 & 3 & & & 3 & & & 3 & 1 & 3 & & 3 & & 1 & & \\
\hline RSP 2 & 0.44 & $4.21 \%$ & 9 & 3 & & & 3 & 9 & & & & & 3 & & 3 & & 3 & & \\
\hline RSP 3 & 0.43 & $4.12 \%$ & 10 & & 9 & & & & 9 & 1 & & & 1 & & 3 & & & 3 & 3 \\
\hline RSP 4 & 1.29 & $12.36 \%$ & 4 & & & & & & & & & & & 3 & & 9 & & & \\
\hline RSP 5 & 1.98 & $18.97 \%$ & 2 & & & & & & & & & & & 9 & & 9 & & 3 & 3 \\
\hline RSP 6 & 1.41 & $13.51 \%$ & 3 & & & & & 1 & & & & 9 & & & & & & & \\
\hline RSP 7 & 2.66 & $25.48 \%$ & 1 & & & 9 & 3 & & 1 & 3 & 1 & & & & 3 & & 3 & & \\
\hline RSP 8 & 0.60 & $5.75 \%$ & 6 & & & 3 & & 1 & & & 1 & 9 & & & & & & & \\
\hline RSP 9 & 0.53 & $5.08 \%$ & 7 & & & & & & & & & & & 3 & & & & 9 & 9 \\
\hline RSP 10 & 0.46 & $4.41 \%$ & 8 & & & & & 1 & & & & 9 & & & & & 9 & & \\
\hline \multicolumn{4}{|c|}{ Ch Absolute Importance $\left(\mathrm{Al}_{\mathrm{Ch}}\right)$} & 1.96 & 5.79 & 23.94 & 9.30 & 8.35 & 3.09 & 8.41 & 5.18 & 22.87 & 3.67 & 23.28 & 12.51 & 29.43 & 14.08 & 12.00 & 12.00 \\
\hline \multicolumn{4}{|c|}{ Ch Relative Importance $\left(\mathrm{RI}_{\mathrm{Ch}}\right)$} & $1.0 \%$ & $3.0 \%$ & $12.2 \%$ & $4.8 \%$ & $4.3 \%$ & $1.6 \%$ & $4.4 \%$ & $2.6 \%$ & $11.7 \%$ & $1.9 \%$ & $11.9 \%$ & $6.4 \%$ & $15.0 \%$ & $7.2 \%$ & $6.1 \%$ & $6.1 \%$ \\
\hline
\end{tabular}




\subsection{Phase II of the QFDforPSS method}

The second phase of QFDforPSS is aimed at the definition of the most critical components of both the service and the product (Table 5). The components, as well as the co-relational strengths (i.e. the values of the relationship matrix), were decided through a meeting carried out with the company's group of experts (due to a non-disclosure agreement with the company some data are omitted).

Table 5. List of PCos and SCos.

\begin{tabular}{|l|l|l|l|}
\hline \multicolumn{2}{|l|}{ Product Components (PCos) } & \multicolumn{2}{c|}{ Service Components (SCos) } \\
\hline PCo1 & Full HD monitor & SCo1 & $\begin{array}{l}\text { Provision of a sufficient number of } \\
\text { maintenance technicians }\end{array}$ \\
\hline PC02 & Touch-screen monitor & SC02 & Decentralization of the service centres \\
\hline PC03 & Automated self-test & SC03 & Extended customer care service; \\
\hline PC04 & Low environmental impact filters & SC04 & Operators periodic training; \\
\hline PC05 & Treatments' data storage system & SC05 & Customer care periodic training \\
\hline PC06 & Range of warnings & SC06 & Qualification of training instructors \\
\hline PC07 & $\begin{array}{l}\text { Remote operational monitoring } \\
\text { system }\end{array}$ & SCo7 & Maintenance technicians' periodic training \\
\hline
\end{tabular}

Notably, the components of the services were defined as per the required type of resources for their realization (Sakao, Song, \& Matschewsky, 2017). Consequently, they were classified into human resources, information, and service tools (Table 6).

Table 6. Classification of SCos.

\begin{tabular}{|c|c|c|}
\hline Human Resources & Information & Service Tools \\
\hline SCo1 & $\mathrm{SCo} 4$ & SC08 \\
\hline $\mathrm{SCo} 2$ & SCo5 & \\
\hline SCo3 & & \\
\hline SCo6 & & \\
\hline SCo7 & & \\
\hline
\end{tabular}

The definition of the product components followed a similar syntax by focusing on the components 
ensuring the availability and operability of the equipment, as well as its environmental performance (Table 7).

Table 7. Classification of PCos.

\begin{tabular}{|c|c|c|}
\hline Operability & Availability & Environment \\
\cline { 1 - 2 } PCo1 & PCo3 & PCo4 \\
\hline PCo2 & PCo6 & \multicolumn{1}{|}{} \\
\cline { 1 - 2 } PCo5 & PCo 7 & \\
\cline { 1 - 2 } & &
\end{tabular}

Then, their assessment was performed by means of the same criteria used previously, where the relationships between PChs and SChs from one side, and PCos and SCos from the other, were evaluated with a 1-3-9 rating scale (Table 8). 
Table 8. QFD for PSS phase II.

\begin{tabular}{|c|c|c|c|c|c|c|c|c|c|c|c|c|c|c|c|c|c|c|}
\hline & 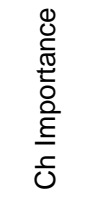 & 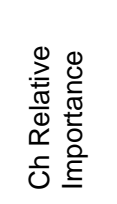 & 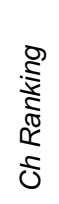 & $\overrightarrow{0}$ & $\begin{array}{l}\text { Oे } \\
\text { Q }\end{array}$ & O̊ & $\begin{array}{l}\text { J } \\
\text { On }\end{array}$ & O্ & $\begin{array}{l}0 \\
0 \\
0 \\
0\end{array}$ & $\hat{0}$ & 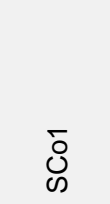 & $\begin{array}{l}N \\
\text { U్ } \\
\text { Un }\end{array}$ & 芯 & 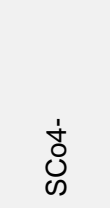 & $\begin{array}{l}\text { L } \\
\text { On }\end{array}$ & 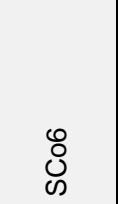 & 它 & $\begin{array}{l}\infty \\
0 \\
ن \\
c\end{array}$ \\
\hline PCh1 & 1.96 & $1.0 \%$ & 16 & & 1 & & 1 & 1 & & & & & & & & & & \\
\hline PCh2 & 5.79 & $3.0 \%$ & 12 & 9 & 9 & & & & & & & & & & & & & \\
\hline PCh3 & 23.94 & $12.2 \%$ & 2 & & & 3 & & & & 9 & 1 & & & 9 & 1 & 3 & 9 & \\
\hline PCh4 & 9.30 & $4.8 \%$ & 9 & & & & & & & & & & & & & & & \\
\hline PCh5 & 8.35 & $4.3 \%$ & 11 & 1 & 1 & 9 & & & & & & & & & & & & \\
\hline PCh6 & 3.09 & $1.6 \%$ & 15 & 1 & & 3 & & & 9 & & & & & & & & & \\
\hline PCh7 & 8.41 & $4.3 \%$ & 10 & & & 9 & & & & 3 & & & & & & & & \\
\hline PCh8 & 5.18 & $2.6 \%$ & 13 & & & 1 & & 9 & & & & & & & & & & \\
\hline PCh9 & 22.87 & $11.7 \%$ & 4 & & & & 9 & & & & & & & & & & & 9 \\
\hline PCh10 & 3.67 & $1.9 \%$ & 14 & & 3 & & & & & & & & & 9 & 3 & & & \\
\hline SCh1 & 23.28 & $11.9 \%$ & 3 & & & & & & 9 & 1 & & & 1 & 3 & 3 & & 9 & \\
\hline SCh2 & 12.51 & $6.39 \%$ & 6 & & & & & & & & & & & 9 & & 3 & & \\
\hline $\mathrm{SCh} 3$ & 29.43 & $15.0 \%$ & 1 & & & & & 1 & & 3 & 9 & 9 & 3 & & 1 & & 3 & \\
\hline SCh4 & 14.08 & $7.2 \%$ & 5 & & & & & & & 3 & & 3 & 1 & & & & & 9 \\
\hline SCh5 & 12.00 & $6.1 \%$ & 7 & & & & & & & & & & 9 & & 3 & & & \\
\hline SCh6 & 12.00 & $6.1 \%$ & 7 & & & & & & & & 1 & & 3 & & 9 & & & \\
\hline \multicolumn{4}{|c|}{ Co Absolute Importance $\left(\mathrm{Al}_{\mathrm{C}_{0}}\right)$} & 63.55 & 73.43 & 237.11 & 207.79 & 78.01 & 237.33 & 394.50 & 300.81 & 307.11 & 269.65 & 430.92 & 278.22 & 109.35 & 513.27 & 332.55 \\
\hline \multicolumn{4}{|c|}{ Co Relative Importance $\left(\mathrm{RI}_{\mathrm{co}_{0}}\right)$} & $1.7 \%$ & $1.9 \%$ & $6.2 \%$ & $5.4 \%$ & $2.0 \%$ & $6.19 \%$ & $10.3 \%$ & $7.9 \%$ & $8.0 \%$ & $7.0 \%$ & $11.2 \%$ & $7.3 \%$ & $2.9 \%$ & $13.4 \%$ & $8.7 \%$ \\
\hline
\end{tabular}


To better analyse the results of the case study, the group of experts was asked to assess the RSPs, PChs, SChs, PCos and SCos using the traditional QFD approach. Based on the outputs of the customers' questionnaires concerning the CRs' importance levels (Section 4.1), the experts assessed the importance of each RSP using a 1 (not important) to 5 (extremely important) rating scale. While the same values of the FAHP relationships matrices were used to derive the relevance of the PChs, SChs, PCos and SCos. This allowed us to better examine the effectiveness of the proposed approach. First, concerning the RSPs, a more accurate rating through the FAHP approach was obtained compared with the traditional QFD. As shown in Figure 3, the traditional QFD approach provided limited results as the variation range of the RSPs was of 13\% while the FAHPQFD approach denoted a wider variation range of 21\%. In addition, through the traditional QFD approach, several RSPs were allocated equal importance levels making a proper distinction between them unfeasible (e.g. RSPs 1, 3, 4, 9); whereas the FAHP approach provided distinct levels for each RSP, leading to the elimination of "ties" among the customers' expectations (Franceschini \& Maisano, 2015).

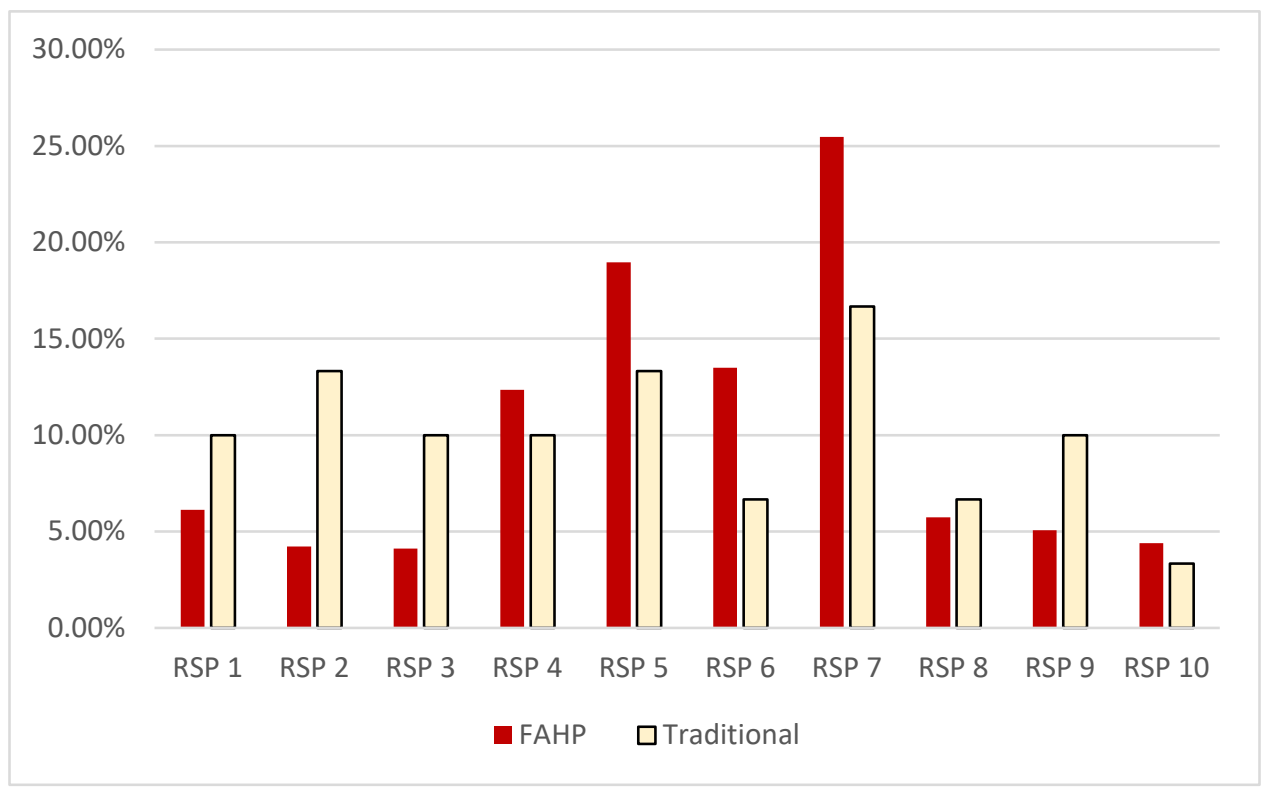


Figure 3. Comparison of the relevance of the RSPs between the FAHP and traditional QFD approaches.

Secondly, the relevance of the characteristics resulting from the FAHP-QFD method was compared to the ones obtained through the traditional QFD method (Figure 4). The results from the FAHP showed a higher variation range (14\%) compared to that of the traditional approach (9 \%) allowing the manufacturer to better prioritize the PSS characteristics.

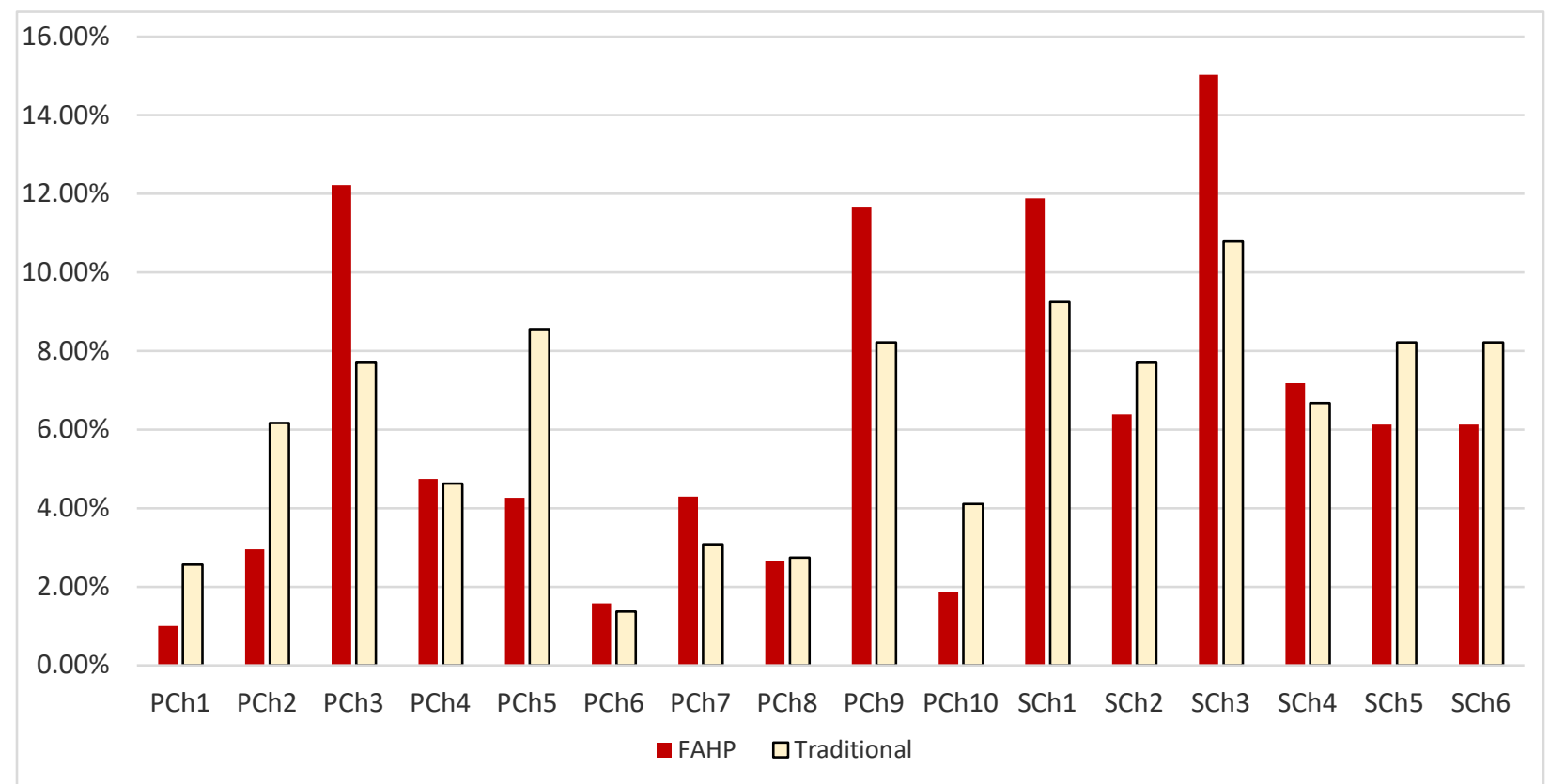

Figure 4. Comparison of the PSS Characteristics' relevance between the FAHP and traditional QFD approaches.

Similarly, the relevance of the PSS components was compared (Figure 5) enabling a better distinction of the PSS Components as the variation range using the FAHP approach (12\%) is higher compared to that of the traditional approach (10\%). It should be noted that these results might be affected by a potential bias due to the differences existing between the target customers and the responses of the group of experts when applying the traditional QFD. To limit such an effect, the above-mentioned experts were asked to apply the method before knowing the results of the FAHP procedure. Moreover, to obtain a more objective assessment, they were interviewed separately, 
and the scores obtained to fulfil the relationship matrices represent the average values of their responses.

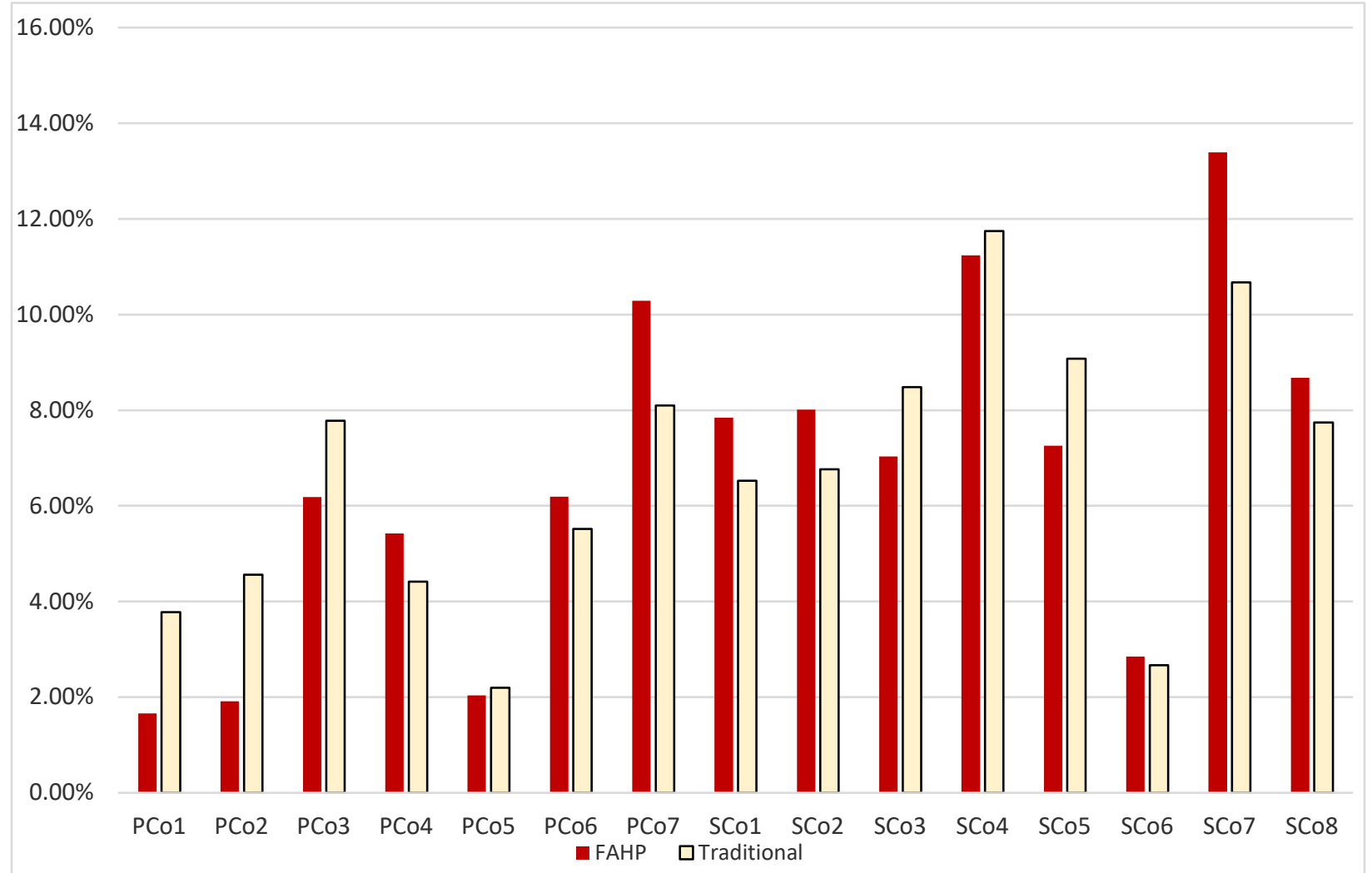

Figure 5. Comparison of the PSS Components’ relevance between the FAHP and traditional QFD approaches.

\section{Discussion of results}

\subsection{Case study results}

The proposed procedure filtered and analysed the high-level “front-end” requirements defined by the customers. The requirements were transformed by means of the Kano model criteria into RSPs according to which the customer judges his overall satisfaction with the solution. In order to address their ambiguity and intangibility, the FAHP was adopted making use of a systematic series 
of pairwise comparisons followed by a consistency check. The FAHP integration with QFDforPSS (sections 4.4 and 4.5) allowed a more sensible evaluation of the RSPs and accordingly a more accurate evaluation of the importance of the product and service characteristics and components. This is in line with Singh and Prasher (2017), who underlined the benefits of the FAHP in assessing the customers' requirements and preferences in a precise manner, notably in the healthcare industry. More in detail, the study allowed us to identify and classify the most relevant product and service characteristics leading to an increase in customer value. As it can be noted in Table 9, the most important characteristics concern the service, apart from the need for availability (PCh3) and the attention paid to the supply of environmentally friendly consumables (PCh9).

Table 9. Relevance of Product and Service Characteristics.

\begin{tabular}{|l|c|c|}
\hline PSS Characteristics & $\begin{array}{c}\text { Relevance } \\
\text { (FAHP) }\end{array}$ & Ranking \\
\hline SCh3 - Time for response & $15.0 \%$ & 1 \\
\hline PCh3 -MTBF & $12.2 \%$ & 2 \\
\hline SCh1 - Information for intervention requests & $11.9 \%$ & 3 \\
\hline PCh9 - Eco-friendliness of consumables & $11.7 \%$ & 4 \\
\hline SCh4 - Calendar time of consumables delivery & $7.2 \%$ & 5 \\
\hline SCh2 - Calendar time of training & $6.4 \%$ & 6 \\
\hline SCh5 - Operational time of customer care & $6.1 \%$ & 7 \\
\hline SCh6 - Quality of customer care & $6.1 \%$ & 8 \\
\hline PCh4 - Software modularity & $4.8 \%$ & 9 \\
\hline PCh7 - Self-testing system & $4.3 \%$ & 10 \\
\hline PCh5 - Number of setup operations & $4 ., 3 \%$ & 11 \\
\hline PCh2 - Monitor type & $3.0 \%$ & 12 \\
\hline PCh8 - Treatments' data storage & $2.6 \%$ & 13 \\
\hline PCh10 - Quality of product manual & $1.9 \%$ & 14 \\
\hline PCh6 - Alarm warnings & $1.6 \%$ & 15 \\
\hline PCh1 - Product size & $1.0 \%$ & 16 \\
\hline
\end{tabular}

Note: Grey lines denote service characteristics.

Similarly, the second phase of the method brought to light the importance of the service components, highlighting the interventions that the company can carry out to augment its PSS 
value (Table 10).

Table 10. Relevance of Product and Service Components.

\begin{tabular}{|l|c|c|}
\hline PSS Components & $\begin{array}{c}\text { Relevance } \\
\text { (FAHP) }\end{array}$ & Ranking \\
\hline SC07- Maintenance technicians periodic training & $13.4 \%$ & 1 \\
\hline SC04- Operators periodic training & $11.2 \%$ & 2 \\
\hline PCo7- Remote operational monitoring system & $10.3 \%$ & 3 \\
\hline SCo8- Range and quality of different types of solutes & $8.7 \%$ & 4 \\
\hline SCo2- Number of service centres & $8.0 \%$ & 5 \\
\hline SCo1- Number of maintenance technicians & $7.9 \%$ & 6 \\
\hline SCo5- Customer care periodic training & $7.3 \%$ & 7 \\
\hline SCo3- Extended customer care service & $7.0 \%$ & 8 \\
\hline PCo6- Range of warnings & $6.2 \%$ & 9 \\
\hline PCo3- Automated self-test & $6.2 \%$ & 10 \\
\hline PCo4- Low environmental impact filters & $5.4 \%$ & 11 \\
\hline SCo6- Number of training instructors & $2.9 \%$ & 12 \\
\hline PCo5- Treatments' data storage system & $2.0 \%$ & 13 \\
\hline PCo2- Touch-screen monitor & $1.9 \%$ & 14 \\
\hline PCo1- Full HD monitor & $1.7 \%$ & 15 \\
\hline
\end{tabular}

Note: Grey lines denote service components.

The comparative assessment denotes the FAHP's capability to handle PSS characteristics and components in a clearer and more distinct manner and to quantify the subjectivities and ambiguities embedded in a PSS as hinted by Huang and Hsu (2016).

\subsection{Effectiveness of the proposed procedure}

The results achieved show that the FAHP integration can allow a clearer evaluation and differentiation of the expected characteristics and performances of the PSS, supporting the research outcome by Kannan (2008) in a PSS context. In other words, we can argue that such an integrated approach augmented the effectiveness of the QFDforPSS method by improving the understanding of the PSS customers' requirements by reducing the uncertainties of the relationships between “hows" (i.e. the RSPs) and " whats” (i.e. PChs and SChs). This answers the RQ2 raised in Section 1. 
The decision-making process described in Section 3 can effectively support engineers in filtering the general customers' requirements to separate basic needs from the ones that have a higher potential to increase the value of the offering. This answers the RQ1 proposed in Section 1. In fact, this novel use of the Kano model can make the adoption of the QFDforPSS method easier and more effective: on the one hand, QFDforPSS allows a better management of the PSS design requirements, since adopting RSPs instead of VoC (i.e. the customer requirements) improves the comparability between multiple RSPs. This contributes to maintain the coherency and alignment of the "whats" in the HoQ (Fargnoli and Sakao 2017). Accordingly, it can be considered as a contribution to the development of methodologies for the elicitation and management of PSS design requirements, as this specific field is still scarcely investigated and needs further investigations (Song 2017). Such a need is outlined also by Sousa-Zomer and Cauchick Miguel (2017b), who carried out a review of latest studies on PSS requirements elicitation and evaluation models. On the one hand, like this type of studies, the present research considers the problems related to requirement evaluation, as well as subjectivity and vagueness. On the other hand, our approach differs in proposing a methodology based on the RSPs' elicitation as a means of enabling a more coherent and balanced assessment of the PSS requirements expressed by different types of stakeholders, while reducing the uncertainties that characterize the relationships between the traditional "hows" and "whats" in the HoQ.

From a service implementation perspective, it has to be pointed out that the results suggest strengthening and innovating the relationships and interactions with the customers. This empirical finding is in line with the insights remarked among others by Gebauer and Kowalkowski (2012). This implies that the company has to focus on increasing its capability in running a service network distributed at a local level, as well as in improving the knowledge and skills of the service and the 
customer care operators. The study contributes to the practical needs of manufacturers that deal with the necessity to find a good balance between the improvement of product and service components to provide offerings that are more convenient. This is also in line with the research results by numerous researchers (e.g. (Baines, Lightfoot, Benedettini, \& Kay, 2009; Fargnoli, De Minicis, \& Tronci, 2014; Haber \& Fargnoli, 2017b; Pezzotta, Pirola, Pinto, Akasaka, \& Shimomura, 2015)), who suggested a framework to define strategies to deliver competitive integrated product-service offerings.

In addition, our research work represents an attempt to answer the need to further investigate the opportunities of improving competitive capabilities and customer satisfaction in a PSS context (Jeong \& Oh, 1998; Oliva \& Kallenberg, 2003; Long, Wang, Zhao, \& Jiang, 2016;

Pan \& Nguyen, 2015; Ulaga \& Reinartz, 2011), even though they are often linked to the specific case study and cannot be easily generalized as argued by Bertoni, Rondini, and Pezzotta (2017).

Moreover, the developed approach is based on an “extended QFD” methodology, where the proposed tools are quite widespread and well-known in the quality engineering and marketing fields, hence the potential users in the manufacturing industries are supposed to be numerous.

\subsection{Managerial implications}

When an offering is related to both a product and a set of connected services, difficulties arise for the company, which mainly consist in the shift from product performance requirements (e.g. the hemodialyzer availability, or the eco-friendliness and the biocompatibility of consumables) to target values in terms of PSS receivers (e.g. maintenance service response within a certain time, the equipment MTBF, etc.). The study remarked the importance of a proper management of customers' needs and expectations. 
Moreover, the shift from traditional CRs to RSPs can be difficult for inexperienced managers and practitioners, risking to opt for solutions that might reduce the customers' satisfaction. Such a finding is also consistent with the outputs of other studies (e.g. Kumar \& Reinartz 2012; Martinez, Bastl, Kingston, \& Evans, 2010; Raddats, 2011; Song, 2017) and represents a novelty in the sector of medical devices (a specific case of the so-called "Product Lifecycle Services”, as per Ulaga and Reinartz (2011)), where usually manufacturers need to ensure the proper functioning of the equipment throughout all of its lifecycle stages (as it happens in a regulated market, where basic requirements are contractual requirements). In addition, such an approach also contributes to the needed empirical studies on Kano’s applications suggested by Materla et al. (2017).

Another contribution of the paper is the presentation of a concrete case of PSS design, including the exemplification of the service characteristics and service components, classified according to a proper taxonomy and assessed in a less complex manner by targeting the resources behind each service activity instead of the activity itself (Sakao et al. 2017). This contribution is more relevant to practice in the industry, but it is useful to advance scientific knowledge regarding ontologies in the PSS domain (Ki Moon, Simpson, Shu, \& Kumara, 2009).

From a more general perspective, the proposed approach facilitates a continuous feedback, which can support engineers to better manage the PSS development activities by verifying the inputs and outputs of each step. This allows the reduction of mistakes and neglections in decisionmaking, mitigating the need for additional resources at later stages of the PSS development process (e.g. redesigning or reassessing the solution's characteristics). Accordingly, the methodology can allow the company to reduce the lead-time (i.e. the response to customers) while optimizing the 
use and allocation of its resources (e.g. better management of maintenance interventions, training provided to customers, etc.).

\subsection{Limitations}

Despite these positive contributions, the present study certainly presents some limitations. Firstly, we did not consider costs, given that the company's core business is in the public procurement sector, ruled by calls for tenders and thus subject to a price-control system. Nevertheless, we are aware that to properly evaluate and select an improvement strategy a financial analysis is needed.

From the company perspective, activities such as “increase the number of service centres”, “increase the number of maintenance technicians” or "supply a higher range of different types of solutes” have a different financial impact. Thus, a cost-benefit analysis should be integrated into the model to obtain results that are more complete. Moreover, the proposed approach can be defined as mono-dimensional (i.e. a business-to-customer approach), since the relationships with other companies, such as original equipment manufacturers, maintenance service providers etc., were not considered. It has also to be noted that benchmarking issues were not discussed in the present study, since this was not the goal of the paper and because our case study was carried out in a regulated market.

In addition, the problem of a relatively high ratio of non-respondents among the interviewed customers and a relatively small number of respondents needs to be remarked. Even though a larger sample of complete responses by customers can allow a more accurate understanding of their requirements (Yin, 2011), the number of complete responses collected is in line with the sampling size suggested in several studies concerning qualitative case study research (Gentles Charles, Ploeg, \& McKibbon, 2015; Marshall, Cardon, Poddar, \& Fontenot, 2013; Yip, Phaal, \& Probert, 2014). 
Nevertheless, the outputs of this study do not rely on quantitative results, since by means of an instrumental qualitative case study the focus is represented by the generation of propositions that are deemed to be wider (Baxter \& Jack, 2008; Ghesquière, Maes, \& Vandenberghe, 2004). In other words, the authors' intention of showing quantitative results follows the findings of Sabbagh et al. (2016), who suggested strengthening the results of qualitative studies by conducting surveys to increase their generalizability.

Furthermore, the results were obtained from a single case study and lack external validity according to Le Dain, Blanco, and Summers (2013). Hence, while caution is required in generalizing the findings beyond the sample and industry concerned (Alam \& Perry, 2002), the use of a single case-study as a research tool for exploratory investigation and to generate new understandings is recognized by several authors (e.g. Piercy \& Rich, 2009; Voss et al., 2002; Yin, 2003).

\section{Conclusions and further work}

This paper proposes a procedure to translate customer needs into PSS functionalities, as well as to explicitly describe the implementation of a PSS tailored to satisfy the real market expectations in the sector of medical devices and the users' (customers') needs. In addition to the extant studies (Arai \& Shimomura, 2005; Sakao et al., 2009; Pezzotta, Pirola, Rondini, Pinto, \& Ouertani, 2016) on the QFDforPSS method, its practical application was discussed considering the manufacturer point of view (e.g. when a set of services is evaluated by different receivers). Hence, its integration with the FAHP method allowed us to further reduce the ambiguity concerning the proper understanding and interpretation of needs and expectations of the PSS final receivers.

Value creation in product-service offerings varies considerably from industry to industry (Velamuri, Bansemir, Neyer, \& Möslein, 2013). Our study provides practical insights into the 
nature of the PSS in the sector of medical devices, ruled by a public procurement market. Further research work is required to deal with the study limitations, especially for what concerns PSS involving multiple stakeholders. The case study is limited to one area of the medical device sector and its generalization is hindered: a larger customer sample with a higher number of respondents could extend the study's perspective representing the state of PSSs in the medical sector more accurately. On the one hand, the type of results achieved can be considered exploratory and used to define new research questions and hypotheses (Kayyar, Ameri, \& Summers 2012). On the other hand, the proposed procedure, like any other novel approach, should be carried out in different contexts (multiple-case study approach (Reddy, 2015)) and industries to refine it, as well as to check its validity and applicability as indicated by several authors (e.g. Alam \& Perry, 2002; Gómez-López, Serrano-Bedia \& López-Fernández, 2016; Hammersley, 2012).

Lastly, the extension of the QFDforPSS method by means of the Analytic Network Process (ANP) approach (Saaty, 2004) to examine the relationships between the "whats" and "hows" of each matrix could be beneficial in better understanding the inter- and intra-relationships that tie the PSS characteristics and components.

\section{Acknowledgments}

This research was supported in part by the Mistra REES (Resource Efficient and Effective Solutions) program (No. 2014/16), funded by Mistra (The Swedish Foundation for Strategic Environmental Research).

The authors would like to thank Mr Giuseppe Palladino, $\mathrm{PhD}$, for his effort and contribution to the case study development. 


\section{References}

1. Abdolshah, M., \& Moradi, M. (2013). Fuzzy quality function deployment: an analytical literature review. Journal of Industrial Engineering, 2013. Article ID 682532:11.

2. Akao, Y. (1990). Quality function deployment: Integrating customer requirements into product design. Cambridge, MA: Productivity Press.

3. Alam, I., \& Perry, C. (2002). A customer-oriented new service development process. Journal of Services Marketing, 16(6), 515-534.

4. Arai, T., \& Shimomura, Y. (2005). Service CAD system - evaluation and quantification. CIRP Annals Manufacturing Technology, 54(1), 463-466.

5. Asadabadi, M.R. (2014). A hybrid QFD-based approach in addressing supplier selection problem in product improvement process. International Journal of Industrial Engineering Computations, 5(4), 543-560.

6. Aurich, J. C., Mannweiler, C., \& Schweitzer, E. (2010). How to design and offer services successfully. Journal of Manufacturing Science and Technology, 2, 136-143.

7. Azevedo, S. G., Govindan, K., Carvalho, H., \& Cruz-Machado, V. (2013). Ecosilient Index to assess the greenness and resilience of the upstream automotive supply chain. Journal of Cleaner Production, 56, 131146.

8. Baines, T. S., Lightfoot, H. W., Benedettini O., \& Kay, J. M. (2009). The servitization of manufacturing: A review of literature and reflection on future challenges. Journal of Manufacturing Technology Management, 20(5),547-567.

9. Baines, T. S., Ziaee Bigdeli, A., Bustinza, O.F., Shi, G., Baldwin, J.S., \& Ridgway, K. (2017). Servitization: revisiting the state-of-the-art and research priorities. International Journal of Operations \& Production Management, 37(2).

10. Baxter, P., \& Jack, S. (2008). Qualitative case study methodology: Study design and implementation for novice researchers. The Qualitative Report, 13(4), 544-559.

11. Bereketli, I., \& Genevois, M. E. (2013). An integrated QFDE approach for identifying improvement strategies in sustainable product development. Journal of Cleaner Production, 54, 188-198.

12. Bergman, M. A., \& Lundberg, S. (2013). Tender evaluation and supplier selection methods in public procurement. Journal of Purchasing and Supply Management, 19(2), 73-83.

13. Bertoni, M., Rondini, A., \& Pezzotta, G. (2017). A systematic review of value metrics for PSS design. Procedia CIRP, 64, 289-294.

14. Buckley, C. C. (1994). Delphi technique supplies the classic result? The Australian Library Journal, 43(3), 158-164.

15. Büyüközkan, G., Ertay, T., Kahraman, C., \& Ruan, D. (2004). Determining the importance weights for the design requirements in the house of quality using the fuzzy analytic network approach. International Journal of Intelligent Systems, 19(5), 443-461.

16. Carnevalli, J. A., \& Miguel, P. A. C. (2008). Review, analysis and classification of the literature on QFDTypes of research, difficulties and benefits. International Journal of Production Economics, 114(2), 737754.

17. Carnevalli, J. A., Miguel, P. A. C., \& Calarge, F.A. (2010). Axiomatic design application for minimizing the difficulties of QFD usage. International Journal of Production Economics, 125(1), 1-12.

18. Chan, L. K., \& Wu, M. L. (2002). Quality function deployment: A literature review. European Journal of Operational Research, 143(3), 463-497.

19. Cheng, B. W., \& Chiu, W. H. (2007). Two-dimensional quality function deployment: an application for deciding quality strategy using fuzzy logic. Total Quality Management, 18(4), 451-470.

20. Cho, I. J., Kim, Y. J., \& Kwak, C. (2016). Application of SERVQUAL and fuzzy quality function deployment to service improvement in service centres of electronics companies. Total Quality Management and Business Excellence, 27(3-4), 368-381.

21. Chowdhury, M. M. H., \& Quaddus, M. A. (2016). A multi-phased QFD based optimization approach to sustainable service design. International Journal of Production Economics, 171, 165-178.

22. Fargnoli, M. (2005). An integrated approach for the development and management of environmentally conscious products. In: Proc. of Environmentally Conscious Design and Inverse Manufacturing, Eco Design (2005). 
23. Fargnoli, M., De Minicis, M., \& Tronci, M. (2012). Product's life cycle modelling for eco-designing productservice systems. In DS 70: Proc. of DESIGN 2012, the 12th International Design Conference. Dubrovnik, Croatia.

24. Fargnoli, M., Costantino, F., Tronci, M., \& Bisillo, S. (2013). Ecological profile of industrial products over the environmental compliance. International Journal of Sustainable Engineering, 6(2), 117-130.

25. Fargnoli, M., De Minicis, M., \& Tronci, M. (2014). Design Management for Sustainability: An integrated approach for the development of sustainable products. Journal of Engineering and Technology Management, 34, 29-45.

26. Fargnoli, M., \& Sakao, T. (2017). Uncovering differences and similarities among Quality Function Deployment based methods in Design for X-benchmarking in different domains. Quality Engineering, 29 (4), 690-712.

27. Fargnoli, M., Costantino, F. Di Gravio, G. \& Tronci M. (2018). Product service-systems implementation: A customized framework to enhance sustainability and customer satisfaction. Journal of Cleaner Production, 188, 387-401.

28. Finster, M., Eagan, P., \& Hussey, D. (2001). Linking industrial ecology with business strategy: creating value for green product design. Journal of Industrial Ecology, 5(3), 107-125.

29. Franceschini, F., \& Maisano, D. (2015). Prioritization of QFD customer requirements based on the law of comparative judgments. Quality Engineering, 27(4), 437-449.

30. Franceschini, F., Galetto, M., Maisano, D., \& Mastrogiacomo, L. (2015). Prioritisation of engineering characteristics in QFD in the case of customer requirements orderings. International Journal of Production Research, 53(13), 3975-3988.

31. Gebauer, H. \& Kowalkowski, C. (2012). Customer-focused and service-focused orientation in organizational structures. Journal of Business and Industrial Marketing, 27(7), 527-537.

32. Gelderman, C. J., Ghijsen, P. W. T., \& Brugman, M. J. (2006). Public procurement and EU tendering directives-explaining non-compliance. International Journal of Public Sector Management, 19(7), 702-714.

33. Geng, X., Chu, X., Xue, D., \& Zhang, Z. (2010). An integrated approach for rating engineering characteristics' final importance in product-service system development. Computers and Industrial Engineering, 59(4), 585-594.

34. Gentles, S. J., Charles, C., Ploeg, J., \& McKibbon, K. A. (2015). Sampling in qualitative research: Insights from an overview of the methods literature. The Qualitative Report, 20(11), 1772-1789.

35. Ghesquière, P., Maes, B., \& Vandenberghe, R. (2004). The usefulness of qualitative case studies in research on special needs education. International Journal of Disability, Development and Education, 51(2), 171-184.

36. Gómez-López, R., Serrano-Bedia, A., \& López-Fernández, M. (2016) Motivations for implementing TQM through the EFQM model in Spain: an empirical investigation, Total Quality Management \& Business Excellence, 27(11-12), 1224-1245.

37. Green, M. H., Davies, P., \& Ng, I. C. L. (2017). Two strands of servitization: A thematic analysis of traditional and customer co-created servitization and future research directions. International Journal of Production Economics, 192, 40-53.

38. Haber, N., \& Fargnoli, M. (2017a). Designing product-service systems: a review towards a unified approach. In: Proc. of the International Conference on Industrial Engineering and Operations Management - IEOM 2017, Rabat, Morocco, April 11-13, 817-837. ISBN: 978-0-9855497-6-3. ISSN: 2169-8767

39. Haber, N., \& Fargnoli, M. (2017b). Design for product-service systems: a procedure to enhance functional integration of product-service offerings. International Journal of Product Development, 22(2), 135-164.

40. Hakanen, T., Helander, N., \& Valkokari, K. (2016). Servitization in global business-to-business distribution: The central activities of manufacturers. Industrial Marketing Management, 63, 167-178.

41. Hammersley, M. (2012). Troubling theory in case study research. Higher Education Research \&Development, 31(3), 393-405.

42. Hara, T., Arai, T. \& Shimomura, Y. (2009). A CAD system for service innovation: integrated representation of function, service activity, and product behaviour. Journal of Engineering Design, 20(4), 367-388.

43. Hatzopoulos, V., \& H. Stergiou. (2011). Public procurement law and health care: from theory to practice. Health Care and EU Law, 413-451.

44. Huang, S.S., \& Hsu, W.K. (2016). An Assessment of Service Quality for International Distribution Centers in Taiwan - A QFD Approach with Fuzzy AHP. Maritime Policy \& Management, 43(4), 509-523.

45. Jeong, M., \& Oh, H. (1998). Quality function deployment: An extended framework for service quality and customer satisfaction in the hospitality industry. International Journal of Hospitality Management, 17(4), 375-390. 
46. Jiao, J., \& Chen, C. H. (2006). Customer requirement management in product development: a review of research issues. Concurrent Engineering, 14(3), 173-185.

47. Kahraman, C., Ertay, T., \& Büyüközkan, G. (2006). A fuzzy optimization model for QFD planning process using analytic network approach. European Journal of Operational Research, 171(2), 390-411.

48. Kamvysi, K., Gotzamani, K., Andronikidis, A., \& Georgiou, A. C. (2014). Capturing and prioritizing students' requirements for course design by embedding Fuzzy-AHP and linear programming in QFD. European Journal of Operational Research, 237(3), 1083-1094.

49. Kano, N., Seraku, N., Takahashi, F., \& Tsjui, S. (1984). Attractive quality and must-be quality. Hinshitsu 14(2),147-156

50. Kannan, G. (2008). Implementation of fuzzy quality function deployment in an automobile component to improve the quality characteristics, Quality Engineering, 20(3), 321-333.

51. Kayyar, M., Ameri, F., \& Summers, J. D. (2012). A case study of the development of a design enabler tool to support frame analysis for Wright Metal Products, a US SME. International Journal of Computer Aided Engineering and Technology, 4(4), 321-339.

52. Ki Moon, S., Simpson, T. W., Shu, J. \& Kumara, S.R.T. (2009). Service representation for capturing and reusing design knowledge in product and service families using object-oriented concepts and an ontology. Journal of Engineering Design, 20(4),413-431

53. Kim, S., \& Yoon, B. (2012) Developing a process of concept generation for new product-service systems: a QFD and TRIZ-based approach. Service Business 6, 323-348.

54. Kumar, V., \& Reinartz, W. (2012). Customer relationship management issues in the business-to-business context. Customer Relationship Management, Berlin: Springer-Heidelberg.

55. Kwong, C. K., \& Bai, H. (2013). Determining the Importance Weights for the Customer Requirements in QFD Using a Fuzzy AHP with an Extent Analysis Approach. IIE Transactions, 35(7), 619-626

56. Le Dain, M. A., Blanco, E., \& Summers, J. D. (2013). Assessing design research quality: investigating verification and validation criteria. In: DS 75-2: Proceedings of the 19th International Conference on Engineering Design (ICED13), Design for Harmonies, Vol. 2: Design Theory and Research Methodology, Seoul, Korea, 19-22.08. 2013.

57. Lee, C. K. M., Ru, C.T.Y., Yeung, C.L., Choy, K.L., \& Ip, W.H. (2015). Analyze the healthcare service requirement using fuzzy QFD. Computers in Industry, 74, 1-15.

58. Lee, Y. C., Sheu, L. C., \& Tsou, Y.G. (2008). Quality function deployment implementation based on Fuzzy Kano model: An application in PLM system. Computers and Industrial Engineering, 55(1), 48-63.

59. Li, T., He, T., Wang, Z. \& Zhang, Y. (2016). A QFD-based evaluation method for business models of product service systems. Mathematical Problems in Engineering 16. doi:10.1155/2016/8532607.

60. Lingg, M., Merida-Herrera, E., Wyss, K., \& Durán-Arenas, L. (2017). Attitudes of orthopedic specialists toward effects of medical device purchasing. International Journal of Technology Assessment in Health Care, 1-8.

61. Liu, H. T. (2009). The extension of fuzzy QFD: From product planning to part deployment. Expert Systems with Applications, 36, 11131-11144.

62. Liu, H. T., \& Tsai, Y. L. (2012). A fuzzy risk assessment approach for occupational hazards in the construction industry. Safety Science, 50, 1067-1078.

63. Liu, H. T., \& Wang, C. (2010). An advanced quality function deployment model using fuzzy analytic network process. Applied Mathematical Modelling, 34, 3333-3351.

64. Lo, S. M., Shen, H. P., \& Shen, J. C. (2016). An integrated approach to project management using the Kano model and QFD: an empirical case study. Total Quality Management and Business Excellence. doi: 10.1080/14783363.2016.1151780

65. Long, H. J., Wang, L. Y., Zhao, S. X., \& Jiang, Z. B. (2016). An approach to rule extraction for product service system configuration that considers customer perception. International Journal of Production Research, 54(18), 5337-5360.

66. Madzík, P. (2016), Increasing accuracy of the Kano model - a case study. Total Quality Management \& Business Excellence. doi:10.1080/14783363.2016.1194197.

67. Marceau, J., \& Basri, E. (2001). Translation of innovation systems into industrial policy: the healthcare sector in Australia. Industry and Innovation, 8(3), 291-308.

68. Marshall, B., Cardon, P., Poddar, A., \& Fontenot, R. (2013). Does sample size matter in qualitative research?: A review of qualitative interviews in IS research. Journal of Computer Information Systems, 54(1), 11-22. 
69. Martinez, V., Bastl, M., Kingston, J., \& Evans, S. (2010). Challenges in transforming manufacturing organisations into product-service providers. Journal of Manufacturing Technology Management, 21(4), 449-469.

70. Materla, T., Cudney, E. A., \& Antony, J. (2017). The application of Kano model in the healthcare industry: a systematic literature review. Total Quality Management and Business Excellence. DOI: 10.1080/14783363.2017.1328980

71. Matschewsky, J., Kambanou, M. L., \& Sakao, T. (2017). Designing and providing integrated product-service systems - challenges, opportunities and solutions resulting from prescriptive approaches in two industrial companies. International Journal of Production Research. doi.org/10.1080/00207543.2017.1332792

72. Matzler, K., \& Hinterhuber, H. H. (1998). How to make product development projects more successful by integrating Kano's model of customer satisfaction into quality function deployment. Technovation, 18(1), 2538.

73. Mittermeyer, S.A., Njuguna, J.A., \& Alcock, J.R. (2011). Product-service systems in health care: case study of a drug-device combination. International Journal of Advanced Manufacturing Technology, 52(9-12), 1209-1221

74. Moultrie, J., Sutcliffe, L., \& Maier, A. (2015). Exploratory study of the state of environmentally conscious design in the medical device industry. Journal of Cleaner Production, 108, 363-376

75. Oliva, R., \& Kallenberg, R. (2003). Managing the transition from products to services. International Journal of Service Industry Management, 14(2), 160-172.

76. Onar, S. Ç., Büyüközkan, G., Öztayşi, B., \& Kahraman, C. (2016). A new hesitant fuzzy QFD approach: An application to computer workstation selection. Applied Soft Computing, 46, 1-16.

77. Pakizehkar, H., Sadrabadi, M. M., Mehrjardi, R. Z., \& Eshaghieh, A. E. (2016). The Application of Integration of Kano's Model, AHP Technique and QFD Matrix in Prioritizing the Bank's Subtractions. Procedia-Social and Behavioral Sciences, 230, 159-166.

78. Pan, J. N., \& Nguyen, H. T. N. (2015). Achieving customer satisfaction through product-service systems. European Journal of Operational Research, 247(1), 179-190.

79. Patriarca, R., Di Gravio, G., Mancini, M., \& Costantino, F. (2016). Change management in the ATM system: integrating information in the preliminary system safety assessment. International Journal of Applied Decision Sciences, 9, 121-138.

80. Pawar, K. S., Beltagui, A., \& Riedel, J. C. (2009). The PSO triangle: designing product, service and organisation to create value. International Journal of Operations \& Production Management, 29(5), 468493.

81. Pezzotta, G., Pirola, F., Pinto, R., Akasaka, F., \& Shimomura, Y. (2015). A Service Engineering framework to design and assess an integrated product-service. Mechatronics 31,169-179.

82. Pezzotta, G., Pirola, F., Rondini, A., Pinto, R. \& Ouertani, M. Z. (2016). Towards a methodology to engineer industrial product-service system - Evidence from power and automation industry. CIRP Journal of Manufacturing Science and Technology, 15,19-32.

83. Piercy, N., \& Rich, N. (2009). Lean transformation in the pure service environment: the case of the call service centre. International Journal of Operations \& Production Management, 29(1), 54-76.

84. Raddats, C. (2011). Aligning industrial services with strategies and sources of market differentiation. Journal of Business and Industrial Marketing, 26(5), 332-343.

85. Raharjo, H., Xie, M. \& Brombacher, A. C. (2011). A systematic methodology to deal with the dynamics of customer needs in Quality Function Deployment. Expert Systems with Applications, 38(4), 3653-3662.

86. Rapaccini, M., Saccani, N. Pezzotta, G., Burger, T., \& Ganz, W. (2013). Service development in productservice systems: a maturity model. The Service Industries Journal, 33(3-4), 300-319.

87. Reddy, K. S. (2015). The state of case study approach in mergers and acquisitions literature: A bibliometric analysis. Future Business Journal, 1(1), 13-34.

88. Regan, W. J. (1963). The service revolution. Journal of Marketing, 47(July), 57-62.

89. Reim, W., Parida, V., \& Ortqvist, D. (2014). Product service systems business models and tactics - a systematic literature review. Journal of Cleaner Production, 97, 61-75.

90. Saaty, T. L. (1990). Decision making for leaders: the analytic hierarchy process for decisions in a complex world. RWS Publications.

91. Saaty, T.L. (2004). Fundamentals of the analytic network process-Dependence and feedback in decisionmaking with a single network. Journal of Systems science and Systems engineering, 13(2), 129-157. 
92. Sabbagh, O., Rahman, M. N. A., Ismail, W. R. \&. Hussain, W. M. H. W. (2016). Methodology implications in automotive product-service systems: a systematic literature review. Total Quality Management \& Business Excellence. doi:10.1080/14783363.2016.1150169

93. Sakao, T. (2007). A QFD-centered design methodology for environmentally conscious product design. International Journal of Production Research, 45(18-19), 4143-4162.

94. Sakao, T., \& Shimomura, Y. (2007). Service Engineering: a novel engineering discipline for producers to increase value combining service and product. Journal of Cleaner Production, 15(6), 590-604.

95. Sakao, T., Napolitano, N., Tronci, M., Sundin, E., \& Lindahl, M. (2008). How are product-service combined offers provided in Germany and Italy? - analysis with company sizes and countries. Journal of Systems Science and Systems Engineering, 17(3), 367-381.

96. Sakao, T., Birkhofer, H., Panshef, V., \& Dörsam, E. (2009). An effective and efficient method to design services: empirical study for services by an investment-machine manufacturer. International Journal of Internet Manufacturing and Services, 2(1), 95-110.

97. Sakao, T., Song, W., \& Matschewsky, J. (2017). Creating service modules for customizing product/service systems by extending DSM. CIRP Annals Manufacturing Technology, 66(1). doi:10.1016/j.cirp.2017.04.107

98. Singh, A., \& Prasher, A. (2017). Measuring healthcare service quality from patients' perspective: using FAHP application. Total Quality Management \& Business Excellence. doi: 10.1080/14783363.2017.1302794

99. Sivasamy, K., Arumugam, C., Devadasan, S. R., Murugesh, R., \& Thilak, V. M. M. (2016). Advanced models of quality function deployment: a literature review. Quality \& Quantity, 50(3), 1399-1414.

100.Song, W., Ming, X., Han, Y., \& Wu, Z. (2013). A rough set approach for evaluating vague customer requirement of industrial product-service system. International Journal of Production Research, 51(22), 6681-6701.

101.Song, W., \& Sakao, T. (2016). Service conflict identification and resolution for design of product-service offerings. Computers and Industrial Engineering, 98, 91-101.

102.Song, W. (2017). Requirement management for product-service systems: Status review and future trends. Computers in Industry, 85, 11-22.

103.Sousa-Zomer, T. T., \& Miguel, P. A. C. (2017a). Exploring business model innovation for sustainability: an investigation of two product-service systems. Total Quality Management \& Business Excellence. doi: 10.1080/14783363.2017.1317588

104.Sousa-Zomer, T. T., \& Miguel, P. A. C. (2017b). A QFD-based approach to support sustainable productservice systems conceptual design. The International Journal of Advanced Manufacturing Technology, 88(14), 701-717.

105.Tan, A.R., Matzen, D., McAloone, T., \& Evans, S. (2010). Strategies for Designing and Developing Services for Manufacturing Firms. CIRP - Journal of Manufacturing Science and Technology, 3(2), 90-97.

106.Temponi, C., Yen, J., \& Tiao, W. A. (1999). House of quality: A fuzzy logic-based requirements analysis. European Journal of Operational Research, 117(2), 340-354.

107.Tontini, G. (2007) Integrating the Kano Model and QFD for Designing New Products. Total Quality Management and Business Excellence, 18(6), 599-612.

108.Tukker, A. (2015). Product services for a resource-efficient and circular economy-a review. Journal of Cleaner Production, 97, 76-91.

109.Tukker, A. (2004) Eight types of product-service system: eight ways to sustainability? Experiences from SusProNet. Business Strategy and the Environment, 13(4), 246-260.

110.Ulaga, W., \& Loveland, J. M. (2014). Transitioning from product to service-led growth in manufacturing firms: Emergent challenges in selecting and managing the industrial sales force. Industrial Marketing Management, 43(1),113-125.

111.Ulaga, W., \& Reinartz, W. J. (2011). Hybrid offerings: how manufacturing firms combine goods and services successfully. Journal of Marketing, 75(6), 5-23.

112.Velamuri, V. K., Bansemir, B., Neyer, A. K., \& Möslein, K. M. (2013). Product service systems as a driver for business model innovation: lessons learned from the manufacturing industry. International Journal of Innovation Management, 17(1):1340004-1-25.

113. Vezzoli, C., \& Ceschin, F. (2015). New design challenges to widely implement 'Sustainable Product-Service Systems'. Journal of Cleaner Production, 97, 1-12.

114. Vinayak, K., \& Kodali, R. (2013). Benchmarking the quality function deployment models. Benchmarking: An International Journal, 20(6), 825-854. 
115.Voss, C., Tsikriktsis, N., \& Frohlich, M. (2002). Case research in operations management. International Journal of Operations \& Production Management, 22(2), 195-219.

116.Wang, C. H., \& Chen, J. N. (2012). Using quality function deployment for collaborative product design and optimal selection of module mix. Computers and Industrial Engineering, 63, 1030-1037.

117.Xie, M., Goh, T. N., \& Tan, K. C. (2003). Advanced QFD applications. ASQ Quality Press.

118.Xing, K., Rapaccini, M., \& Visintin, F. (2017). PSS in healthcare: an under-explored field. Procedia CIRP, 64, 241-246

119. Yin, R. K. (2003). Case study research: design and methods ( $3^{\text {rd }}$ edition). Thousand Oaks: Sage.

120. Yin, R. K. (2011). Qualitative research from start to finish. New York, NY: Guilford Press.

121.Yip, M. H., Phaal, R., \& Probert, D. R. (2014). Stakeholder engagement in early stage product-service system development for healthcare informatics. Engineering Management Journal, 26(3), 52-62.

122.Zare Mehrjerdi, Y. (2010). Quality function deployment and its extensions. International Journal of Quality and Reliability Management 27 (6):616-640.

123.Zhang, X., Tong, S., Eres, H., Wang, K., \& Kossmann, M. (2015). Towards avoiding the hidden traps in QFD during requirements establishment. Journal of Systems Science and Systems Engineering, 24(4), 316336.

124.Zheng, G., Zhu, N., Tian, Z., Chen, Y., \& Sun, B. (2012). Application of a trapezoidal fuzzy AHP method for work safety evaluation and early warning rating of hot and humid environments. Safety Science, 50, 228239. 